\title{
REMEDIANDO OBJETOS DE APRENDIZAGEM: COMO ACENTUAR A ACESSIBILIDADE
}

Luciane Maria Fadel

A tecnologia aplicada em diferentes campos, provoca o surgimento de novos paradigmas, como é o caso dos objetos de aprendizagem. Por definição, são "entidades, digitais ou não, as quais podem ser utilizadas e reutilizadas, ou ainda referenciadas durante o processo de aprendizado com apoio tecnológico" (COMMITTEE, 2002, p. ii, NT). A versão digital dos objetos de aprendizagem beneficiou seu desenvolvimento pois, uma vez colocado num repositório sua reutilização se torna facilitada. Assim, é comum associar a qualidade digital ao objeto de aprendizado, o que implica no design segundo uma linguagem apropriada para esse meio. Acredita-se que essa linguagem é formada pela compreensão do meio conjuntamente com o próprio objeto, para assim apresentar um artefato que possibilita ao usuário reconhecer através da interface as interações possíveis (LAUREL, 1993; MATEAS, 2004).

Uma das formas de compreender o meio e o objeto nele representado é através da remediação (BOLTER e GRUSIN, 1999), pois remediação significa a representação de um meio em outro. Além disso, a versão digital de um objeto de aprendizagem pode também agregar qualidade de acessibilidade. Por acessibilidade entende-se a qualidade do que é acessível (FERREIRA, 2014), a qual é formalizada pelo Art. 8o do DECRETO No 5.296 do governo brasileiro onde a acessibilidade é 'condição para utilização, com segurança e autonomia, total ou assistida, dos espaços, mobiliários e equipamentos urbanos, das edificações, dos serviços de transporte e dos dispositivos, sistemas e meios de comunicação e informação, por pessoa portadora de deficiência ou com mobilidade reduzida'. No espaço digital a promoção da acessibilidade é tratada através de diretrizes (WCAG) desenvolvidas pelo o consórcio internacional World Wide Web Consortium (W3C). Todos os esforços buscam fomentar a criação de artefatos que possam ser utilizados por pessoas com diferentes graus de habilidades visuais, auditivas ou cognitivas.

Esse artigo investiga como um objeto de aprendizagem pode fazer uso das qualidades do meio digital para promover a acessibilidade. Para tanto, investiga-se os diferentes níveis de remediação de um objeto de aprendizagem e argumenta-se que uma remediação mais agressiva contribui com qualidades que facilitam a acessibilidade. Com isso, qualidades de acessibilidade podem ser compreendidas como qualidades do meio e não apenas do artefato. Para construir esse argumento, esse artigo inicia revendo conceitos de remediação, interatividade e agência. Acredita-se que interatividade e agência são qualidades do meio digital os quais contribuem no redesign da nova mídia.

\section{Remediação}

Para Bolter e Grusin o termo remediação pode seguir duas vertentes. A primeira refere-se a relação entre imediação e hipermediação. Por imediação esses mesmos autores entendem como sendo a condição de imersão do usuário no artefato. Assim, a imediação transparente significa o olhar através da tela, como se a tela não existisse, ou seja a mediação desaparece, e o usuário está imerso na experiência mediada. Já na hipermediação o usuário não só vê a tela mas está ciente da mediação. Dessa forma, a 
mídia contemporânea trabalha com a transparência da representação do real e o encantamento da opacidade da própria mídia. O leitor pode oscilar entre manipular as janelas (hipermediação) e ler seu conteúdo (imediação), ou oscilar entre olhar os links e olhar através dos links a linguagem do texto.

A segunda leitura sobre remediação por Bolter e Grusin é sobre o conteúdo, ou seja é "representação de um meio em outro meio" (1999, p. 46, N.T.). Nessa perspectiva os autores descrevem quatro estágios de competição continua entre duas mídias. Num dos extremos desse espectro, a mídia antiga é representada na nova mídia sem nenhuma análise ou crítica. Como exemplo de uma remediação no primeiro nível as primeiras versões em PDF de um texto, ainda não possibilitavam qualquer interação com o texto além de mudar a página. No segundo nível de remediação, a nova mídia enfatiza as diferenças entre a forma eletrônica e a antiga. Nesse caso, o texto passa a ser apresentado ainda em PDF mas agora com as possibilidades de busca, de marcação, comentários etc. No terceiro nível, a remediação provoca um redesign da mídia antiga. Essa nova apresentação toma a forma de um mosaico onde a descontinuidade é clara. Assim, essa transformação da nova mídia poderia ser exemplificada como o ebook (seguindo o exemplo da mídia texto), onde as janelas, botões, barras de rolamento, e outros controles indicam a descontinuidade.

Finalmente, no outro extremo desse espectro a nova mídia absorve completamente a mídia antiga. Por exemplo, o texto agora é apresentado na forma de um livro digital onde o usuário pode identificar no mapa onde as imagens foram fotografadas ou interagir com os infográficos assoprando ou aumentando as imagens (veja o livro Our Choice de Al Gore como exemplo).

\section{Interatividade}

Em seu Modo Multivalente de Interatividade (Multivalent Model of Interactivity) Zimmerman (2004) acomoda diferentes definições de interativo (CAMERON, 1995; CRAWFORD, 2003; LAUREL, 1993) ao propor modos de interatividade. Nesses quatro níveis de engajamento, uma atividade "mais" interativa pode incorporar 1 ou mais modos.

Assim o Modo 1 corresponde a interatividade cognitiva, ou participação interpretativa que acontece quando uma pessoa se envolve psicologicamente, emocionalmente ou intelectualmente com o artefato.

O Modo 2 apresenta a interatividade funcional a qual é a participação utilitária com o texto. Nesse modo são avaliadas as interações funcionais e estru- turais com o artefato, como o fato de ter sumário, o design gráfico etc.

O Modo 3 refere-se ao entendimento mais comum de interatividade ou seja, a interatividade explícita a qual verifica a participação do usuário com as escolhas projetadas e procedimentais no texto. Procura-se analisar nesse modo como o usuário percorre vários caminhos a partir de links , ou segue as regras de uma linguagem de jogo. Alguns pontos verificados são portanto: escolhas, eventos randômicos, simulações dinâmicas, e outros procedimento programados.

No Modo 4 aparece a meta-interatividade ou a participação cultural com o texto. Esse modo deve ser analisado como a experiência externa ao texto, ou seja como a cultura dos fãs a qual se forma pela participação ativa dos usuários em comunidades.

\section{Agência}

Agência pode ser entendida como a percepção de ser responsável por ações significativas e perceber os resultados dessas ações (MURRAY, 2011, p. 127). Isso significa que agência não se trata do número de ações, mas do significado que a ação provoca. Por exemplo, um jogo de xadrez possui poucos movimentos (ações), mas um grau elevado de agência porque esses movimentos são selecionados a partir de uma quantidade enorme de possibilidades e cada qual determina o curso do jogo. Assim, agência é comumente observada em jogos, mas não se restringe a ele como Eichner (2014) argumenta.

Eichner (2014) entende agência como um modo de experiência de mídia, e mais especificamente como envolvimento com a mídia induzida por estratégias textuais (entenda-se texto como artefato midiático). Dessa forma, agência pode ser concebida como operando em 3 níveis: pessoal, criativa e coletiva. A forma fundamental de agência é a pessoal, a qual pode ser compreendida através de diferentes estratégias textuais como: domínio da narrativa, domínio da escolha domínio da ação e domínio do espaço.

Considera-se que o reconhecimento do texto com seus padrões de recursos, e a interpretação do texto com sua polissemia de acordo com a bagagem de cada um é a forma mais básica de envolvimento com o texto e pertence a primeira ordem de envolvimento. O domínio da narrativa pertence a segunda ordem de envolvimento e acontece quando o padrão de recursos clama pela participação do leitor o qual reconhece a estrutura textual que forma a narrativa. Para Eichner isso se baseia em convenções de gênero, como gênero de filmes, ou na provocação consciente da expectativa da audiência com narrativas 
1 Utiliza-se aqui a o termo 'provocação' como sinônimo de "play" definido por Zimmerman (2004) como sendo "Play is the free space of movement within a more rigid structure. Play exists both because of and also despite the more rigid structures of a system”. complexas. Ou seja, explora-se o espaço de movimentos livres do usuário numa estrutura rígidar.

O domínio da escolha acontece quando o usuário sente que sua escolha teve influencia e fez a diferença no resultado final da narrativa.

O domínio da ação está diretamente relacionada com o controle da ação dos personagens, ou seja, fazer o personagem (ou qualquer elemento controlável) andar, pular etc. Isso implica que o domínio da ação depende do que estado de "flow" do usuário (CSIKSZENTMIHALYI, 1990).

O domínio do espaço, como apontado por autores como Murray (1998) e Manovich (2002), revela-se quando o usuário explora o espaço narrativo e navega se orientando nesse padrão estrutural.

\section{Método de pesquisa}

O método Close Reading (VAN LOOY e BAETANS, 2003) foi aplicado para investigar como a remedia- ção agrega qualidades que facilitam a acessibilidade no objeto de aprendizagem "Sólidos" (BUSARELLO, 2015). Assim, o primeiro passo foi observar características gráficas e de interação do objeto. Para tanto o objeto foi utilizado várias vezes, e a cada iteração foram anotadas características especificas, observando-se também como essas características promoviam a imersão ou a opacidade da interface. Para facilitar a revisitação foram feitos screen shots de cada página, ou dos elementos específicos. Tais figuras foram ordenadas numa tabela, onde as colunas seguiram a narrativa de análise na sequencia: Elemento, Função, Efeito, Argumento (ver Tabela 1). Assim elemento pode ser uma composição gráfica composta por um ou mais elementos gráficos, de uma simples seta até a própria página. Como Função entende-se o propósito para o qual o elemento foi inserido na página. Já o Efeito descreve um dos estados da remediação, ou seja, hipermediação ou imediação, bem como qual o modo de interatividade evidenciado pelo objeto. Esse efeito é argumentado pela análise do elemento no conjunto e tendo-se como lente analítica a poética de remediação e interatividade como visto na seção anterior.

\begin{tabular}{|c|c|c|c|}
\hline Elemento & Função & Efeito & Argumento \\
\hline $\begin{array}{c}\text { Saiba } \\
\text { montar } \\
\text { um } \\
\text { TRIEDRO. }\end{array}$ & $\begin{array}{l}\text { Desvio para o conteúdo } \\
\text { sobre o triedo: abre outra } \\
\text { página }\end{array}$ & $\begin{array}{l}\text { Hipermediação } \\
\text { Interatividade explicita }\end{array}$ & $\begin{array}{l}\text { Escolher o desvio } \\
\text { requer consciência } \\
\text { da ação, ou seja que } \\
\text { o usuário enxergue a } \\
\text { interface }\end{array}$ \\
\hline
\end{tabular}

Tabela 1: Exemplo da a narrativa de análise

\section{Objeto de análise: Sólidos}

O método Close Reading foi aplicado no objeto de aprendizagem "Sólidos" criado por Raul Inácio Busarello (Figura 1). Esse objeto conta a história de três piratas e sua jornada para encontrar um tesouro. Os conceitos de projeção cilíndrica e épura estão inseridos na história e fazem parte de seu roteiro (Figura 2). O desenvolvimento do objeto como Busarello explica com mais detalhes no capítulo desse livro "Gamificação como estratégia na construção de objeto de aprendizagem em história em quadrinhos" segue o formato de hipermídia com vários caminhos possíveis levando ao mesmo final. A história conta a trajetória de 3 piratas desde a leitura do mapa de um tesouro o qual está no formato de triedro, até a descoberta do tesouro.
Como o objeto é voltado a aprendizagem , é natural ter um maior numero de paginas para explicar o conteúdo. Do total de 205 paginas que compõem o objeto, 38 se referem a história propriamente dita, enquanto 102 páginas apresentam o conteúdo sobre sólidos (Figura 3). Além dessas, 5 páginas são de exercícios e 60 são páginas auxiliares sem conteúdo que servem para organização ou apresentar uma mensagem de pausa ou erro para o usuário.

O quadro 18 apresenta a possibilidade de 3 caminhos diferentes. Cada um desses caminhos é percorcício do mesmo domínio de conteúdo e ao mesmo final da história. rido por um dos 3 piratas mas todos levam a exer- 

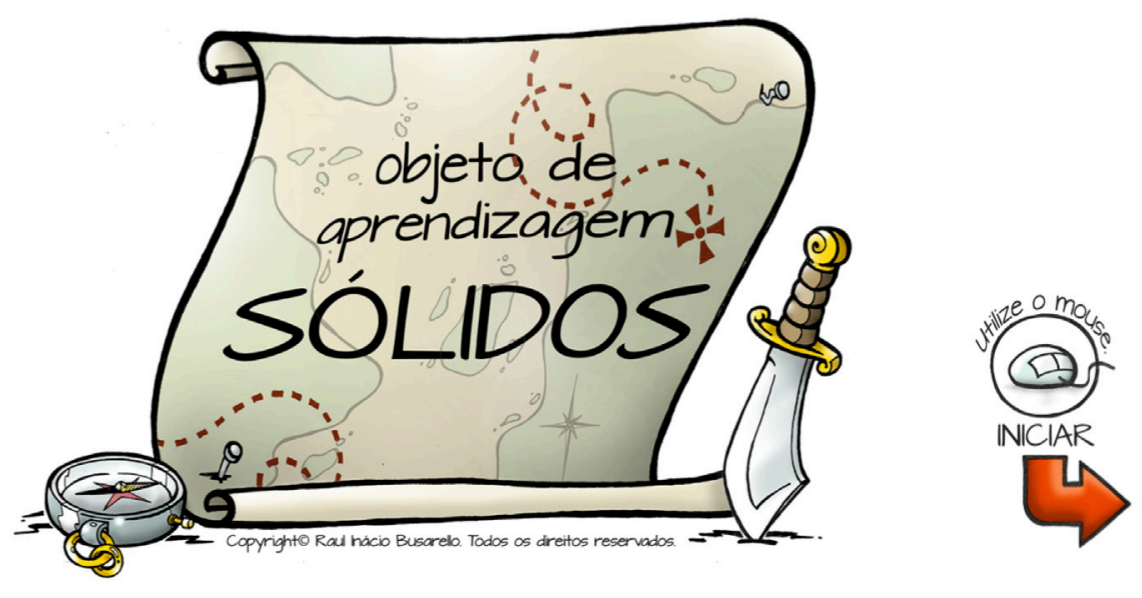

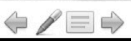

Figura 1: Página inicial do objeto de aprendizagem "Sólidos" de Raul Busarello

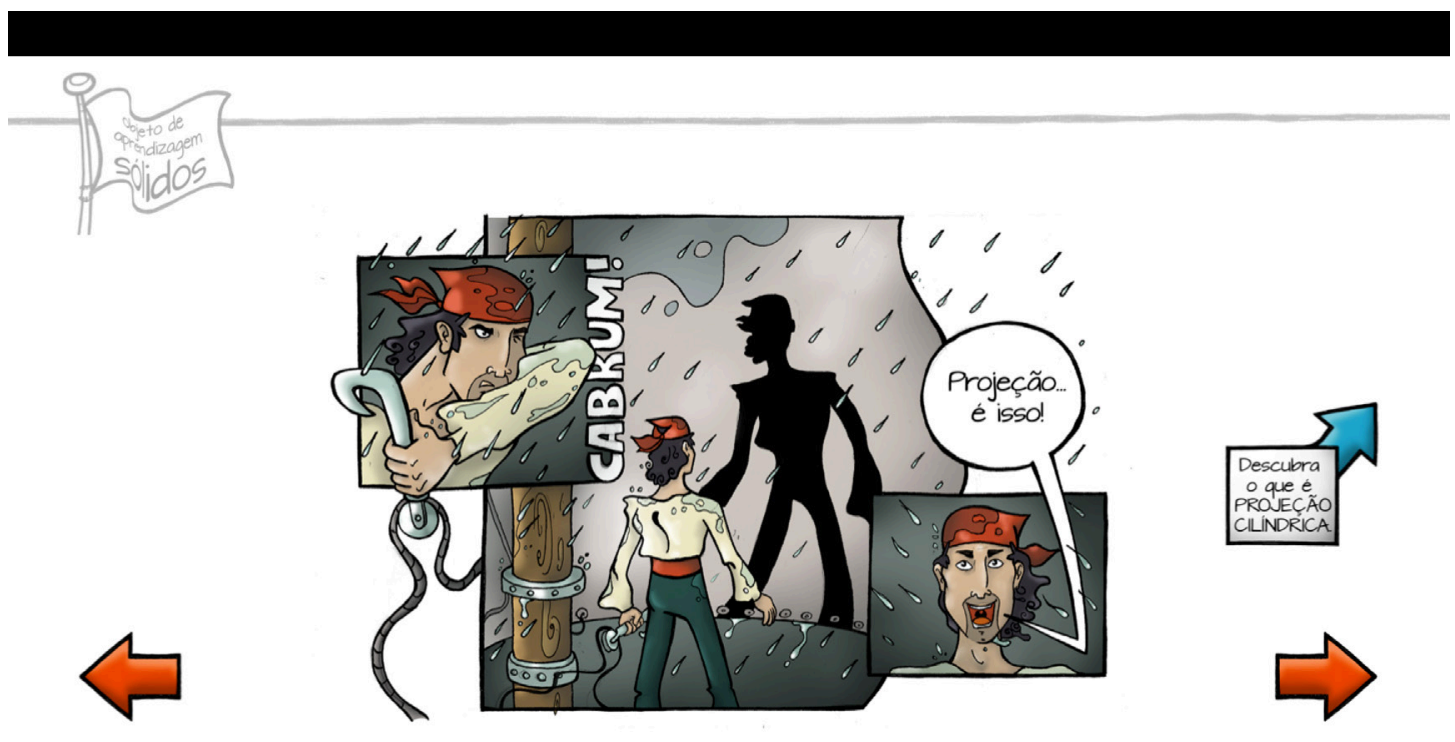

Figura 2: Página inicial do objeto de aprendizagem "Sólidos" de Raul Busarello 


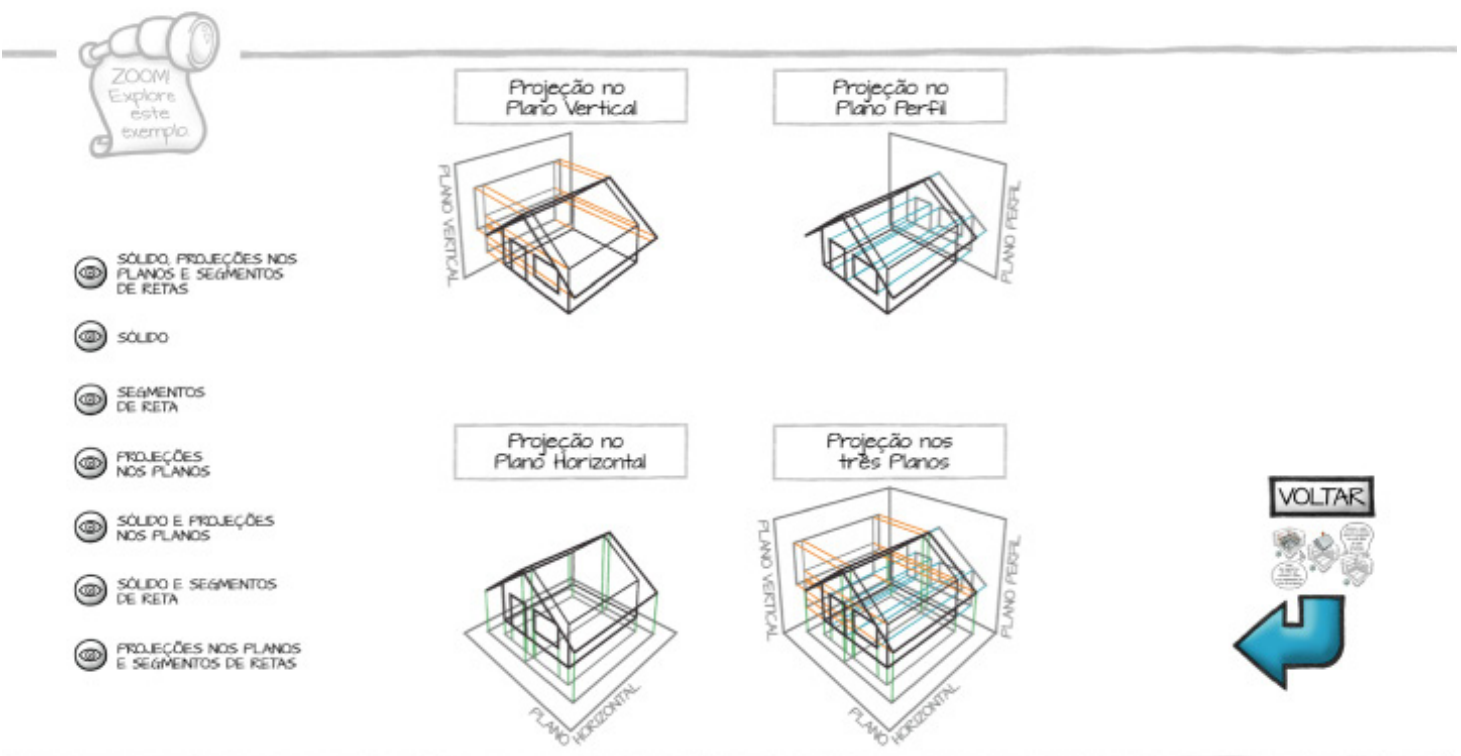

Figura 3: Exemplo de página de conteúdo

\section{A Leitura de "Sólidos"}

\section{Interatividade}

Olhando pela lente analítica da interatividade, verifica-se que a interatividade cognitiva e explícita sobressaem-se sobre a funcional ou metainteratividade. A interatividade cognitiva se molda principalmente pela participação emocional com o artefato, pois o leitor é chamado a guiar os personagens criando um grau de responsabilidade pelo sucesso do personagens.

A interatividade explicita é marcada pelos pontos de controle para virar a página da narrativa principal (seta simples vermelha), para outras informa- ções sobre um determinado assunto (seta diagonal azul), para virar essas páginas sobre um assunto especifico (seta simples azul), para os desafios (seta em arco vermelha), e links colocados sobre elementos específicos dos quadros (portas, detalhes, etc), e para pausa (pergaminho).

Sendo um objeto de aprendizagem é razoável identificar um maior número de páginas formadas por conteúdo referente ao tema, que nesse caso são sólidos. Nessas páginas a interatividade explícita sustenta a hipermediação uma vez que o objeto requer que o usuário aprenda a teoria sobre sólidos. Nesse caso, a opacidade da interface é reforçada pelo próprio personagem o qual se dirige diretamente ao usuário (ver Figura 4). 

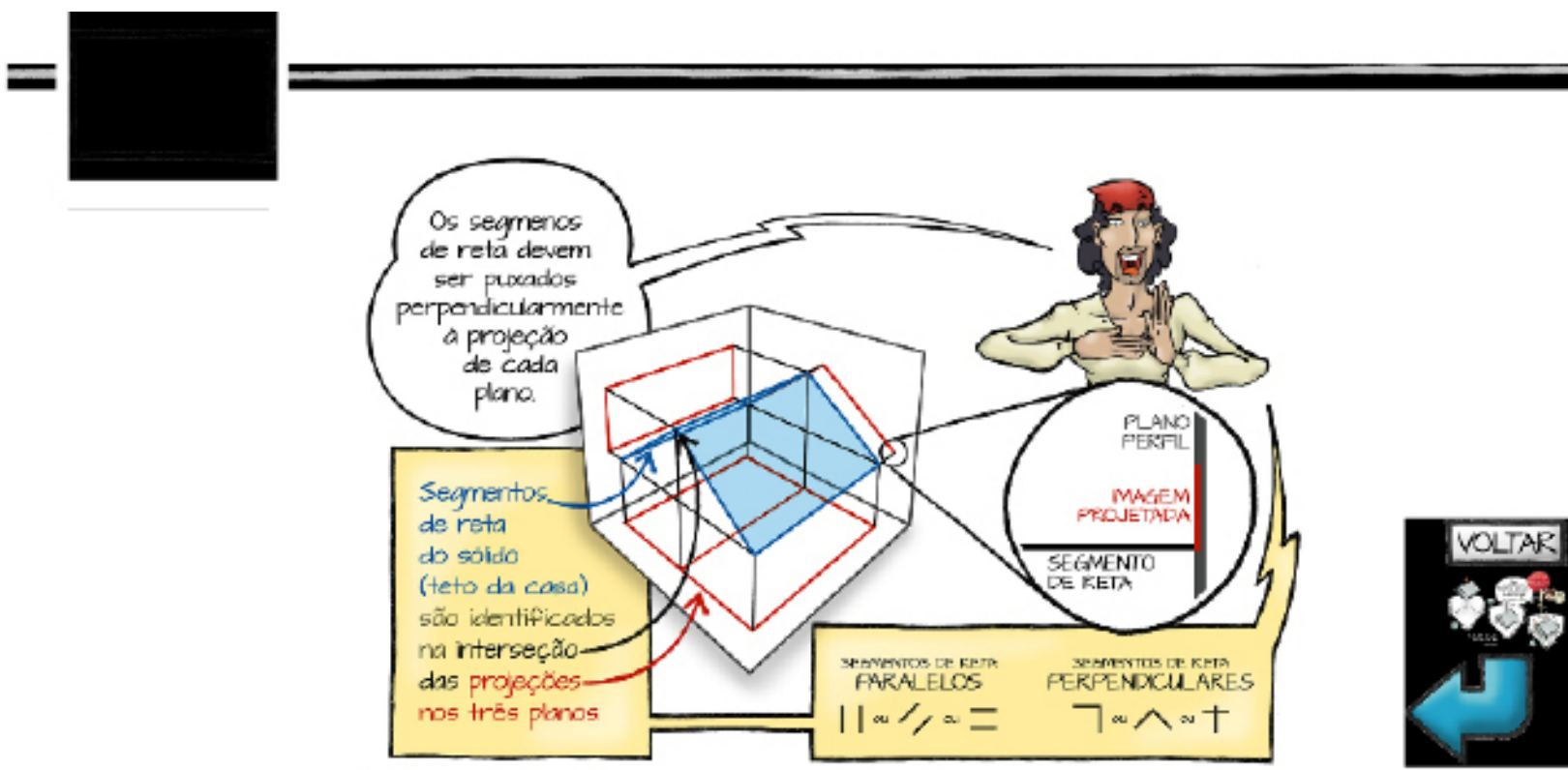

Figura 4: Página de conteúdo onde o personagem se dirige ao usuário

\section{Remediação}

A remediação pode ser interpretada nesse objeto de aprendizagem por suas duas vertentes: remediação como oscilação entre imediação e hipermediação e remediação como representação de uma mídia antiga numa nova mídia.

A oscilação é constante ao percorrer o objeto "Sólidos", pois a imediação é projetada através da imersão na história, enquanto a hipermediação acontece pela participação ativa do leitor através das escolhas.

Considerando remediação como a representação de uma mídia antiga numa mídia recente, é evidente que Sólidos remedia a história em quadrinhos. Aliás a própria descrição de Busarello afirma que se trata de um "objeto de aprendizagem, com base em histórias em quadrinhos hipermídia gamificado". Ainda olhando para essa definição tem-se o redesign da mídia antiga acrescentando-se características de hipermídias e gamificação.

Antes da análise desse redesign, verifica-se que a história em quadrinhos é representada na nova mídia sem crítica, ou seja, a estética dos quadrinhos são trazidos para o digital sem nenhum redesign expressivo. Busarello trata o quadro como unidade expressiva, e aplica o balão para os diálogos, a multiplicidade de enquadramento e posição de câmera para dramatização e expressar diferentes focalizações. Como na mídia original o uso de onomatopeias constrói a sonoridade do artefato.

O redesign acontece portanto, através da opção de múltiplos caminhos e de se aprofundar no conteúdo, ou seja, acrescentando-se a qualidade de hipertexto à história em quadrinhos.

O conteúdo sobre sólidos é apresentado, também remediando-se uma história em quadrinhos. Essa remediação porém, é agressiva pois provoca um redesign da mídia antiga. Assim, o conteúdo é narrado por um dos piratas dirigindo-se ao usuário. A representação, no formato de história em quadrinho, aproveita-se da representação em quadros da épura e triedro. Nesse momento, as qualidades interativas do meio ficam evidentes para o usuário, pois pode-se ligar e desligar alguns dos elementos das projeções, como segmentos de retas ou projeções nos planos. Dessa forma, consegue-se apresentar o conteúdo no contexto da história, tornado instrutores os próprios personagens.

Além disso o processo de gamificação também pode ser interpretado pela lente da remediação. Nesse 
caso, o objeto remedia um jogo ao adicionar a opção de escolha, como no exemplo da chave, ou nos desafios apresentados. A escolha certa é recompensada por frases de elogios enquanto a escolha errada permite uma nova tentativa. Logo o erro, como no jogo é visto como uma possibilidade de tentar de novo, como na celebre frase de Samuel Beckett "Ever tried. Ever failed. No matter. Try Again. Fail again. Fail better.” A remediação de um jogo também pode ser vista na possibilidade de escolher diferentes caminhos que levam ao mesmo desfecho final. O desenho da interface sugere ao usuário que percorra os 3 caminhos finais através da chamada para seguir outro caminho. Assim, o enfoque é dado no caminho e nas descobertas que acontecem durante o trajeto ao invés do tempo menor para chegar ao final da história.

\section{Agência Pessoal}

Agência pessoal é gerada pelo objeto Sólidos através do domínio da narrativa e domínio da escolha. Porém, o domínio da narrativa permite ao usuário experienciar agência apenas no final da história, enquanto que o domínio da escolha é presente em todos os momentos.

O domínio da narrativa pertence a segunda ordem de envolvimento e acontece quando o padrão de apelo clama pela participação do leitor o qual reconhece a estrutura textual que forma a narrativa. Para Eichner isso se baseia em convenções de gênero, como gênero de filmes, ou na provocação consciente da expectativa da audiência com narrativas complexas. Ou seja, explora-se o espaço de movimentos livres do usuário numa estrutura rígida².

Assim, o domínio da narrativa pode acontecer quando o padrão de recursos provoca o usuário a participar com a estrutura do texto. Nesse objeto, o usuário levanta hipóteses iniciais sobre como a história vai terminar, e o sentimento de agência vai crescendo ao realizar que o final imaginado é o que realmente acontece na história. A hipótese inicial se baseia no gênero do artefato, ou seja "caça tesouro", e o conhecimento trazido de outras histórias desse gênero alinham com o resultado positivo dessa "caça”. Além disso, algumas dicas passadas pela história, as quais também refletem o entendimento do assunto 'sólidos' pelo pirata mais novo, reforçam que serão bem sucedidos nessa jornada.

Já o domínio da escolha acontece quando o usuário sente (mesmo que momentaneamente) que sua escolha fez a diferença no resultado final do artefato.

A primeira participação direta do leitor acontece na pagina 10 quando é preciso escolher uma das chaves para abrir a porta. Apenas a chave que corresponde com a projeção apresentada é a correta. A escolha da opção correta dá suporte a percepção do domínio da escolha uma vez que essas escolhas individuais irão se somando e revelando uma determinada narrativa, o que também dá suporte ao domínio da narrativa, ou seja a percepção de agência pessoal. Mesmo escolhendo a chave incorreta o domínio da escolha também é vivenciado porque o resultado é uma cena humorística. O uso de humor reforça o mapeamento entre a representação (cena) e a história (BIZZOCCHI, 2014). Essa também é a fórmula utilizada para a escolha da escada que os piratas precisam para vencer os obstáculos do caminho. Se a escolha for a "incorreta" o pirata enfrenta um momento de perigo mas envolto em muito humor. A participação direta acontecerá mais 3 vezes até o final da aventura.

\section{Considerações finais}

O objeto de aprendizagem "Sólidos" remedia principalmente uma história em quadrinhos e um jogo. Essa conclusão reflete a estrutura e estilo de uma forma de mídia no design dessa nova mídia. O conjunto remediado gera um artefato o qual explora a linguagem da nova mídia, através da interatividade e agência os quais contribuem para acessibilidade.

A primeira é a remediação mais óbvia, da história em quadrinhos, e acontece em dois momentos: sem crítica à mídia antiga e é aplicada para contar a história dos piratas que buscam um tesouro; e de forma mais agressiva em relação à mídia antiga para apresentar o conteúdo sobre sólidos. Como a mídia antiga (história em quadrinhos) já apresenta recursos acessíveis para diferentes habilidades auditivas, pois sua estética baseia-se no visual, tais recursos também são evidentes no objeto. Assim, é plenamente concebível a compreensão da história através das imagens. Os quadros reforçam a percepção do tempo, pois cada quadro, ou seja a representação de um momento (MCCLOUD, 1993) encerra um instante e a sequencialidade permite a noção de vários instantes no tempo. O quadro também facilita a compreensão da causalidade, justamente por causa dessa sequencialidade porque o quadro anterior é recebido como causa do próximo quadro. A linguagem de humor reforça o universo sonoro da história através dos gestos exagerados dos personagens e onomatopeias.

Ao emprestar a linguagem dos quadrinhos, o objeto também busca a oscilação entre imersão na história e o encantamento com sua opacidade. Assim, o objeto explora ativamente a dinâmica entre a fronteira da imediação e hipermediação. Enquanto a imediação e o domínio da narrativa intensificam o engajamento com a mídia, a hipermediação motiva explorar os diferentes caminhos. 
Já as páginas que apresentam o material instrucional aplicam camadas de complexidade ao remediar uma história em quadrinhos. Isso acontece através da interatividade explícita e do domínio da escolha. Ambos ampliam a acessibilidade, pois existe equilíbrio entre a linguagem de quadros do triedro e da história em quadrinho, sendo que o personagem quebra a rigidez do espaço bidimensional ao sair por um buraco desenhado (círculo) e orientar o usuário na leitura do conteúdo. O humor, portanto, continua mapeando a representação e a história.

A acessibilidade nesse caso, novamente para pessoas com diferentes habilidades auditivas, recai na visualização do passo a passo de uma tarefa, como desenhar a épura de um sólido, e no controle da visualização de cada elemento. $\mathrm{O}$ humor conforta o erro, e a hipermediação sobressai à imersão. Quando o usuário seleciona o ícone para saber mais sobre o assunto, a história dos piratas é pausada para dar lugar a série de telas que apresentam o conteúdo. Ou seja, a hipermediação é sustentada pela substituição de conteúdo, e em seguida pela constante chamada pela escolha do usuário.

Assim também, a acessibilidade trazida pela remediação de um jogo, pois o objeto evidencia a interação entre escolha e consequência possibilitando sempre o reiniciar. Isso também implica em escolher diferentes caminhos para acompanhar o personagem e assim, reforçar o aprendizado sobre sólidos através de diferentes exercícios que cada personagem precisa resolver. Cada escolha reforça o sentimento de agência facilitando ainda mais a acessibilidade, pois esse sentimento envolve o usuário com a mídia, conectando-o ao artefato através de atividades cognitivas ou emocionais.

Assim, as formas de remediação do objeto de aprendizagem "Sólidos" as quais o projetam ora num nível de incorporação sem mudanças da mídia antiga e ora mais intenso no seu redesign, o caracterizam como um objeto que adota a qualidade digital. E, embora o design desse objeto possa ainda se beneficiar da linguagem e representação que se formam nesse processo de remediação, algumas qualidades de acessibilidade podem ser verificadas. Acredita-se que o domínio do meio e de sua linguagem valorizam a acessibilidade ofertada pelo próprio meio, a qual pode ser explorada em sua plenitude. Para tanto, o processo de remediação intenso, o qual reinventa a mídia antiga, se apresenta como uma abordagem a ser explorada.

\section{Referências}

BIZZOCCHI, J. Narratives - Foundational Concepts. SFU. Vancouver: New Media

Course. 2014.

BOLTER, J. D.; GRUSIN, R. Immediacy, Hypermediacy and Remediation. In: BOLTER, J. D.;

GRUSIN, R. Remediation. Cambridge: MIT Press, 1999. p. 20-50.

BUSARELLO, R. I. Sólidos. [S.l.]. 2015.

CAMERON, A. Dissimulations: Illusions of Interactivity. MFJ, v. 28, Spring 1995.

COMMITTEE, L. T. S. IEEE Learning Technology Standards Committee (LTSC). Draft Standard for Learning Object Metadata, 2002. Disponivel em: <https://biblio.educa.ch/sites/default/ files/20130328/lom_1484_12_1_v1_final_draft_o.pdf>. Acesso em: 05 Maio 2017.

CRAWFORD, C. The art of interactive design. San Francisco: No Starch Press, 2003.

CSIKSZENTMIHALYI, M. Flow: The Psychology of Optimal Experience. New York: Harper Perennial Modern Classics, 1990.

EICHNER, S. Agency and Media Reception: Experiencing Video Games, Film, and Television. Potsdam: Springer VS, 2014. 
FERREIRA, A. B. D. H. Dicionário Aurélio. [S.l.]: Positivo, 2014.

LAUREL, B. Computers as Theatre. Boston: Addison Wesley, 1993.

MANOVICH, L. The Language of New Media. London: The MIT Press, 2002.

MATEAS, M. A Preliminary Poetics for Interactive Drama and Games. In: WARDRIP-FRUIN, N.; HARRIGAN, P. First Person: New Media as Story, Performance and Game. Cambridge: MIT, 2004. p. 19-33.

MURRAY, J. Hamlet on the Holodeck. London: MIT Press, 1998.

MURRAY, J. H. Afordances of the medium. In: MURRAY, J. Inventing the Medium Principles of Interaction Design as a Cultural Practice. Cambridge: MIT Press, 2011. p. 56-92.

VAN LOOY, J.; BAETANS, J. Close Reading New Media: Analysing Electronic Literature. Leuven: Leuven university Press, 2003.

WILEY, D. A. Connecting learning objects to instructional design theory: A definition, a metaphor, and a taxonomy. EEJ Education, 2003.

ZIMMERMAN, E. Narrative, Interactivity, Play, and Games. In: WARDRIP-FRUIN, N.;

HARRIGAN, P. First Person: New Media as Story, Performance, and Game. Cambridge: MIT Press, 2004. p. 77-90. 